\title{
Impact of Influencer Marketing on Consumer Purchase Behavior during the Pandemic
}

\author{
Misshka Guptaa \\ Student \\ Journalism and Mass Communication Graduate \\ Humber College, Toronto
}

\begin{abstract}
Social Media has turned from our regular photos and thought dumping platform to a marketing space mainly led by influencers. Influencers, the ones who influence, hold a firm grasp on people all over social media through their content, views, thoughts, and uniqueness that they have to offer. These influencers are known to impact people especially the younger generations.
\end{abstract}

We can mark them as a new form of marketing that works beyond traditional marketing and is not limited to just selling a product but broadens the horizon to building a brand identity and creating a trustful relation between the audience, the brand, and the influencer. As the number of people who use social media grow, so grows the number of influencers and so does the number of companies choosing to use influencer marketing. The scope is big, the audience is endless and the influencers are professionals at creating engaging marketing content that is a long-term investment for any company big or small.

The aim of this paper is to bring to light the recent uproar of Influencer Marketing on social media during the pandemic and how it has had an impact on companies and on the audience's purchase behavior. The data for this paper has been taken through a small research survey that has also been done on a sample size of 50 consumers to study the impact of influencer marketing on their purchase behavior and decisions. All data used is particular to the pandemic and hence data post-2020 to now has been used.

Keywords: Influencer Marketing, Brand Identity, Consumer Behavior, Sales, Purchase Behavior

\section{Introduction}

Influencer marketing involves marketing products and services on social platforms through influential people on the platform, popularly known as Influencers. Influencers can be Nano, Micro, Macro, and Mega depending on the number of their followers and average engagement on their pages. Since social media is widely popular among individuals of all ages especially youngsters, a lot of these users grew on to become influencers mainly because of their content and what they post. Influencers are, as a lot of social media users have defined, your virtual friends who recommend you products and services through well-curated content. Influencers also work in niches and genres like beauty, food, fashion, lifestyle and create content on their forte genres and hence start building a following and soon achieve the influencer status. Becoming an influencer is directly related to them becoming a trustworthy source for their followers and an opinionated who has thousands of people agreeing with them. This is the key thing that attracts companies to use influencers to market themselves online. They try to get along with an influencer's key audience through the influencer and with the help of some smartly made marketing material, they try to drive sales and attention towards their brand.

As the pandemic hit the world like a wrecking ball, a lot of people took to social media to express themselves through various content on Facebook, Instagram, TikTok, YouTube, and more. As they gained traction and popularity among users, who now flock to the online spaces even more than usual, they also gained valuable brand collaborations that have now turned into a whole marketing prospect in the marketing industry. More and more companies irrespective of their size have dropped all their other marketing plans to invest in Influencer marketing, which as of today is an industry worth billions of dollars.

The recent uprise of influencer marketing is also credited to the flawless compartmentalization of influencers based on their niche and area of interests. Companies pertaining to a particular niche now find it easier to get in touch with influencers who create content on the same niche. Hence it makes it easier for the companies to

1. work closely with people who know their industry and can create content and promotional material with their own expertise in the field, and

2. Get in touch with the influencer's audience who are interested in their industry.

If a beauty influencer promotes a beauty brand, it will reach more of the beauty brand's target audience as the influencer, known for beauty-related content, has most of their followers be either people interested in beauty or people who work in the beauty industry themselves.

While this was a view of the company side, on the consumer side, as they interact more with an influencer they like and consume their content, they grow more trustful of them and hence if they see the influencer promoting a certain beauty brand, they will trust 
their judgment and all the positive things they have to say about the brand and soon enough turn into a consumer of the brand themselves.

This research paper will look exclusively into the impact of influencer marketing on consumers and their purchase behavior as well as any considerable impact it has had on consumers during the pandemic and social media.

\section{Limitations and Advantages}

Limitations

- Inadequate sample size

- Insufficient helpful responses from the survey

- Limited access to data due to limited research on this topic

- Lack of certain information or sources for information taken from social media

- Sudden change in trend or any information used in the paper since the trend of this topic keeps changing

- Narrow view of the entire topic

- Variable data as consumer opinions can change over times

\section{Advantages}

- Very specifically chosen objectives

- Selective and numbered survey subjects

- Popular apps chosen to gather more data

- Target on teens, young adults, and social media users

- Focus on all forms of influencer marketing

- Focus on its effects during the pandemic

- Easy availability of influencer's influence margin

- Survey responses from consumers that have been impacted

\section{Literature Review}

\section{- What is influencer marketing?}

Influence marketing is the development and delivery of advertising messages through influential people, opinion leaders, and not through the brand itself. They influence by example, more so than using word of mouth to explain why someone should buy the product. (Referral Rock Learn, 2020)

Influencer Marketing is a hybrid of old and new marketing tools. It takes the idea of celebrity endorsement and places it into a modern-day content-driven marketing campaign. The main difference in the case of influencer marketing is that the results of the campaign are collaborations between brands and influencers. (Influencer Marketing Hub, 2019)

Influencer marketing involves a brand collaborating with an online influencer to market one of its products or services. Some influencer marketing collaborations are less tangible than that - brands simply work with influencers to improve brand recognition. (Influencer Marketing Hub, 2019)

In recent times influencer marketing has seen tremendous growth as a way of marketing as more and more brands have chosen influencer marketing over traditional means of advertising. Not only have bigger brands have easily shifted to influencer marketing, it has been a key tool for smaller businesses as well.

This research paper dwells deeper into how in the recent times, as a pandemic struck world moved online, influencer marketing got a major grip and grew to massive levels on various social media platforms. It will also dig into how brands and businesses have seen absolute profits and growth in sales and visibility due to influencer marketing.

\section{- $\quad$ Previous and newer trends of influencer marketing and its rise.}

In the next few years, brands are on track to spend billions of dollars on influencer marketing. This form of marketing-currently utilized with great success on Instagram and YouTube - is not a short-lived fad, but a tectonic shift for the future of digital advertising. It's the way of the future, and the responsibility is on business leaders to keep up. Modern marketing professionals looking to adopt influencer marketing for their brands face equally modern challenges. Like finding the right talent, tracking and measuring results and quantifying how this new marketing opportunity aligns with the overall strategy. Influencer Marketing for Brands is the field guide for the digital age. (Levin, 2020)

As stated by Levin, the influencer marketing phenomenon had already been a hit until a pandemic forced more brands to take this route of marketing. While it was already dominating Instagram and youtube, this paper will focus on how it took over more platforms like twitter, TikTok, Tumblr and more.

Influencers play an integral role in social media marketing as vehicles for discovery, inspiration and awareness. The idea of having separate content strategies, social strategies and influencer strategies is a thing of the past. 
Influencer marketing isn't a “fad”, but a complete and necessary part of a holistic marketing strategy. (Makropoulos, 2020)

Brands have definitely taken a risk by shifting from traditional marketing to an influencer based marketing. Over time brands have recorded much more input in terms of sales, interest, visibility, feedback and profits that have created more rock solid influencer marketing strategies in the marketing sector.

\section{- Influencer marketing and its impact on consumer behaviour}

The theme of trust comes up over and over again these days when speaking of influencer marketing and there's a reason for that. People have learned that commercials lie and stars are paid to promote things they don't necessarily care about. While influencers, those individuals have built a following around what they are passionate about, on the other hand, are a lot more likely to only promote products they have thoroughly vetted as they'll lose their following otherwise. This is why their audience trusts them. (Cobain, 2020)

Part of the reason why influencer marketing is gaining steam is also because of ad blocking. Not only do people prefer to hear from influencers; they actually block advertisement. If you look at these trends and numbers it becomes pretty obvious that influencer marketing and user generated content shape consumer buying behaviour and influence their purchases. And while celebrities have reach, micro influencers have power. (Cobain, 2020)

As Cobain mentioned, influencer generated marketing content does play a role in shaping buying behaviour more so because of it being more trustworthy, real, well presented and attractive in nature. Apart from this, the content change that an influencer brings is something regular marketing doesn't hence its impact on audiences and their will to purchase a product immediately increases.

Consumers are more likely to trust peer recommendations, as they're generally considered more trustworthy than claims in brand ads, and social media influencers can be very powerful in this respect. If a product is accepted within their circle, that immediately boosts its reputation and affiliated connection - which means the strongest voices within any group have huge sway over that initial relationship. (Barker, 2020)

Over the recent years, influencer marketing has become increasingly popular, representing a specific type of social media marketing. The aim of this scientific contribution is the systematization of knowledge about the position and roles of influencers as opinion leaders in the social media environment in order to identify their typology, influence factors and the intensity of their impact on consumer decision making process, based on the comparison of knowledge from the results of global research studies and the quantitative online research study processed by authors. The findings of the survey showed that the promotion of some products through influencers may be more advantageous than others. Influencers will have the greatest impact when buying clothes, shoes, cosmetics and, surprisingly, services. Meanwhile, people rely heavily on other factors to buy food, jewelry and electronics, but it is not excluded that influencer marketing could affect them as well. (Stefan Zak, 2020)

In respect to this paper, a more specific approach to the idea of consumer and purchase behaviour is taken. On the same lines as Cobain, this paper deals specifically with how influencer marketing's massive rise during the pandemic has impacted consumers and their purchase habits.

With an increase in influencers, there is definitely as increase in the variety of marketing content from these influencers which has got hold of different audiences who have all been somehow influenced by them to if not buy but get aware of a brand or business and their work.

We've established that consumers place a lot of weight on the recommendations of influencers — but why? Influencers are able to establish trust with their community of followers because they are viewed as experts. In fact, a study by Olapic found that $39 \%$ of consumers rely on an influencer's expertise when weighing the value of their endorsements. Expertise on the internet isn't anything new, but influencers have turned their expertise into a way to impact consumer buying behavior. (Wiley, 2019)

People like people. People trust people. People trust people more than they trust brands and more than they trust marketers.

Influencers are real. The best influencers are honest, know and respect their audience, don't lie about products just to make a buck, and can deliver real value for both brands and the audience of friends and followers they've amassed over the years. Trust is key.

Influencers are also - or can be - entertaining and offer new and exciting ways of sharing a brand's message. They are discovering personalities, products, methods of application, tricks and tips that they are eating up. And they love the influencers who are sharing this information and these products with them. From what I can see, those influencers love them right back. It's a relationship, not a one way sales channel that brands and agencies have been accustomed to in the past. (Kramer, 2019)

\section{- Influencer marketing and various social media platforms}

Many Instagram-users who follow influencers do not mind that promotion and thus influencing is happening. Every Instagrammer is free to follow and unfollow whomever they want. Since it is one's own choice to press the 'follow' button, people are aware that sponsored posts come with certain people they want to follow. Many people follow influencers because they like a certain aspect 
about this person or this person's Instagram, or they feel like they recognize a part of themselves in the influencer. Because of a shared aspect of identity, followers will often also like the products that are being promoted. (Diggit magazine, 2020)

The impact will also relay on the influencer marketing agencies since TikTok over the time forged very strong partnerships with the marketing agencies that enabled brands across the country to put the pedal to the medal with TikTok influencer campaigns. TikTok's emergence was leading to a shift where brands were moving out of mega-influencers in YouTube and Instagram space to micro-influencers on TikTok across the chartered and unchartered territories. (Mahal, 2020)

Popular micro-influencers, like those found on Instagram and Snapchat, are known for their strong engagement rates among niche audiences and a loyal following can be even more powerful on TikTok when influencers tap into their following and weave branded messaging into trending topics and challenges. (Working influencer , 2019)

\section{- Impact of Influencer marketing on company sales}

Influencers on Twitter make your existing advertising efforts work even harder. Our research showed that those who were exposed to brand Tweets had a 2.7x lift in purchase intent over participants who did not see an advertiser Tweet. When participants were exposed to a campaign that featured both brand and influencer Tweets, the lift in purchase intent more than doubled to 5.2x. (Aka, 2016)

A majority of marketers believe that influencer marketing attracts higher-quality customers to their business. This could be because social media users tend to be more affluent and more likely to recommend products to family and friends. Blogs and Facebook are by far the most effective outlets for influencer marketing, dwarfing YouTube, Instagram, and Twitter. 37\% said blogs were their most effective platform, and 25\% said Facebook. (Foster, 2019)

Marketers rated influencer marketing as their fastest-growing channel for acquiring customers online. Organic search and email are too mature to provide the same yearly growth that influencer marketing now delivers. Affiliate marketing and display advertising performed poorly, scoring below $10 \%$. Influencer marketing is quickly becoming one of the most important online marketing channels. Budgets are growing fast, and marketers are seeing strong returns. The vast majority of marketers are generating real revenue from influencer marketing. With returns like this, budgets will keep increasing for the foreseeable future. (Foster, 2019)

It's important to note that those "influenced consumers" are all of different age groups, and on average 55 percent of those consumers who discovered new products, services, and brands through social media influencers, vloggers, niche bloggers, and celebrity endorsers left a product review in the last month. Those numbers are higher than the average digital consumer behavior and, for brands in search of reviews that give their products credibility and lead to purchases, significant. (Kramer, 2019)

\section{Research Findings}

A total sample size of 50 consumers of all age groups were surveyed to understand the influence of influencer marketing on their purchase decisions and its impact during the pandemic especially. The data is interpreted and incorporated in the graphs and diagrams below.

The survey participants consisted of young people from ages 13-30 who are all avid social media users and a consumer of many social media trends. The survey had 10 questions including name, age, and various questions about their knowledge of influencer marketing, personal experience with it, and how the trend works out for them.

The survey produced the following results: 
Q 1 What are social media platforms that these users spend more time on?

\section{Social Media platforms most popular among users}

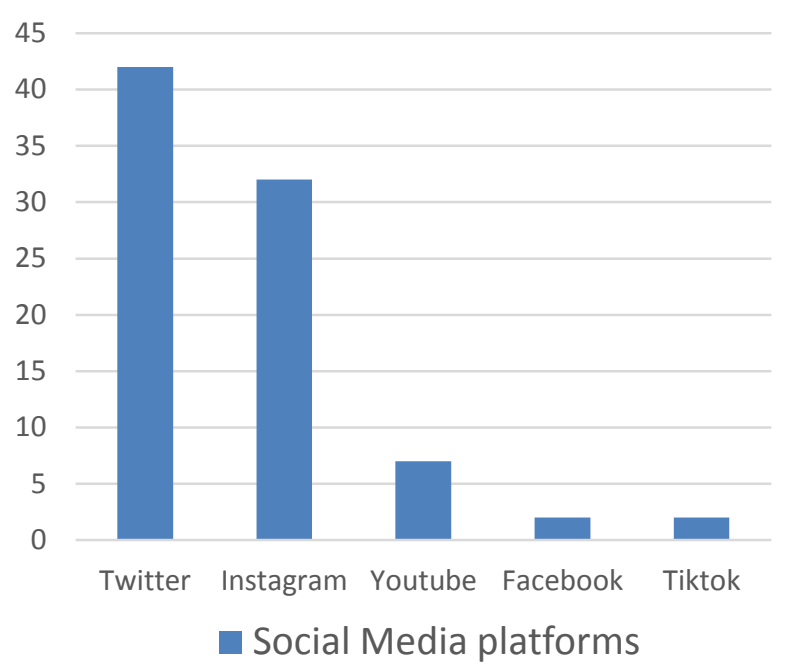

A majority of people from this sample size of 50 picked Twitter and Instagram as social media platforms they use the most while Facebook and TikTok were the least used, YouTube held a middle-ground. This data points to how platforms with the most number of influencers: Twitter and Instagram also have a high number of users and users who spend a lot of time on these platforms hence coming in contact with influencer marketing content frequently.

TikTok also has a hard grip on influencer marketing to the point where TikTok influencers move to Instagram to set up a parallel channel to broaden their prospects. Indian consumers unfortunately due to the ban of TikTok cannot enjoy TikTok influencer marketing content but sans India, TikTok is also a hub for viral blown up creators to become influencers who get paid to make 1530 seconds videos for promotion.

While YouTube is a long-form content creation app where a lot more serious and well put together marketing content goes on. Usually established influencers on TikTok, Twitter or Instagram move to YouTube once they get mildly popular and take their brand endorsements with them to create long-form content which is more indulgent and impactful.

\section{Q 2 What niches of influencers do these users follow the most?}

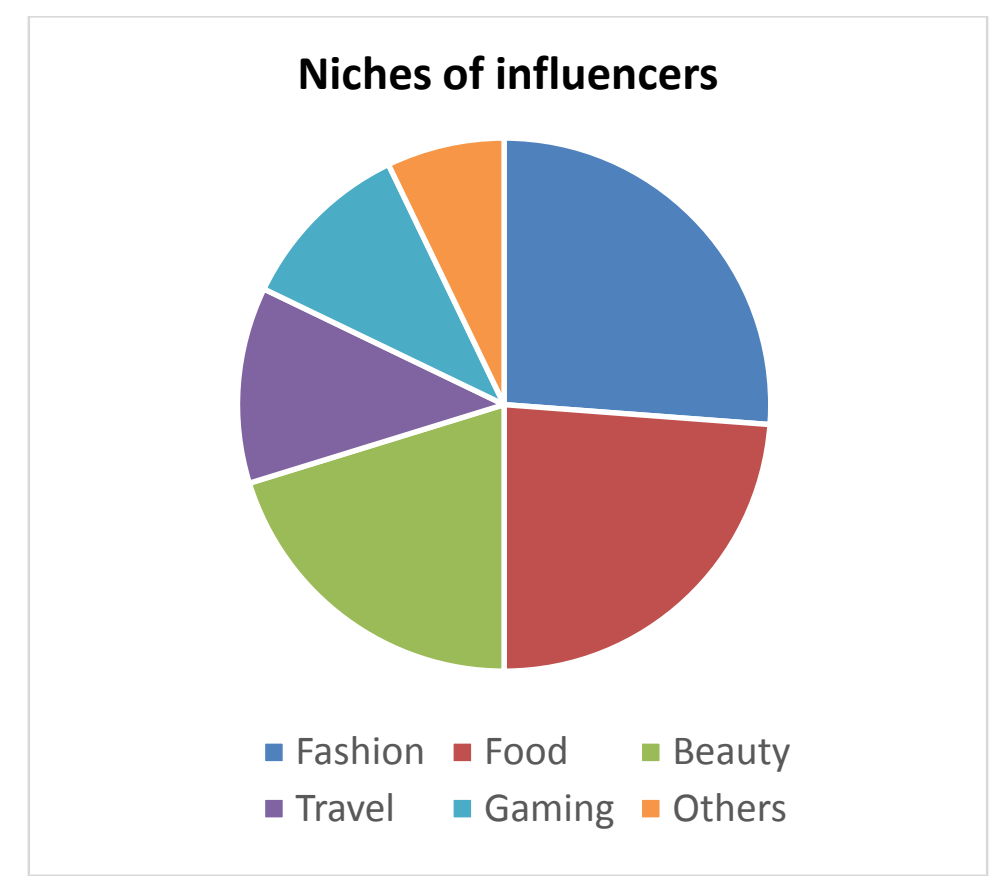

As per the survey results: Fashion, Food, Beauty, Travel, and Gaming Influencers were some of the most popular niches of influencers users follow on social media. Fashion and Beauty as well as Gaming and Food have emerged as really popular forms 
of content online and have seen a considerable growth in the number of influencers who make content in this niche. Due to the pandemic and a severe hit on the travel industry, Travel influencers are not the top chosen niche but are still mildly popular.

Influencer marketing perpetuates a lot among Fashion and Beauty influencers who collaborate with clothing lines and makeup companies and promote them on their own pages. These influencers make content on outfit ideas, makeup looks, reviews, hauls, and much more.

While Gaming influencers engage their audiences in promotional content by joining hands with new game developers, gamer communities, patreons, and exclusive merch collaborations as well as companies that produce gaming essentials like headsets, gaming chairs, gaming setups, monitors, and devices. Their content is mainly streaming videos where they play games and live stream it or play games with fellow gamers or their followers.

Recently, Food blogging has turned into Food influencing where these influencers create content on recipes, food they make, food hacks, trends, and much more. These influencers often promote companies that sell kitchen essentials, ingredients or even market cookbooks and diet plans.

With how useful and entertaining these niche contents are and how people have gained popularity within communities of these niches, it is only valid for companies to scout these influencers and promote themselves through them.

\section{Q 3 Do the influencers these users follow promote any brand or product? Or have these users come across influencer- promoted content on social media?}

\section{Have the influencers you follow ever promoted a brand or business through their content? Or have you seen influencers in general make content promoting a brand and their products? \\ 50 responses}

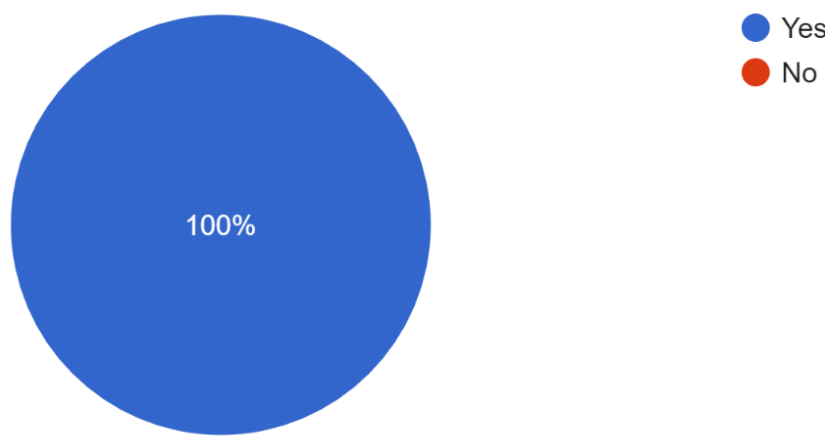

The survey delivered a $100 \%$ positive result for this question as every user mentioned YES to seeing influencers they follow or influencers on social media promote a brand, business, and product.

This solidifies that influencer marketing and content produced out of a marketing collaborating between influencers and companies have widespread reach and almost every user on social media has come across such promotional material while navigating through social platforms irrespective of whether its from influencers they follow or influencers who ended up on their feeds due to algorithm and interactions.

And a noticeable increase in the visibility and frequency of this content has been reported during the pandemic as traditional marketing took a severe hit and a majority of companies turned to influencer marketing to maintain their brand and sales.

With how compartmentalized the influencer marketing industry is and how social media algorithms work, users are often suggested similar content to what they have shown interest in, which also includes influencer-promoted promotional content that makes its way to their feeds. This results in users coming across influencer-marketed content more frequently and hence points towards the excessive use of this marketing form on social media.

\section{Q 4 How did users see influencers incorporate the brand/product in their content for marketing purposes? The options} provided to the users were:

- Made a review video/post

- Mentioned the brand/product in their regular videos/stories/posts

- $\quad$ Made specific content about the product and the brand

- Shared the brand's content on their page and urged their followers to check them out 
- Have shared an exclusive discount code to their followers if they purchase from the brand they are promoting

Users could choose multiple options out of these and share any other form of content they came across.

\section{If you answered YES to the previous question, how have the influencers incorporated brand promotions in their content? If you answered NO plea...hing related to this in the last option if you can! \\ 50 responses}

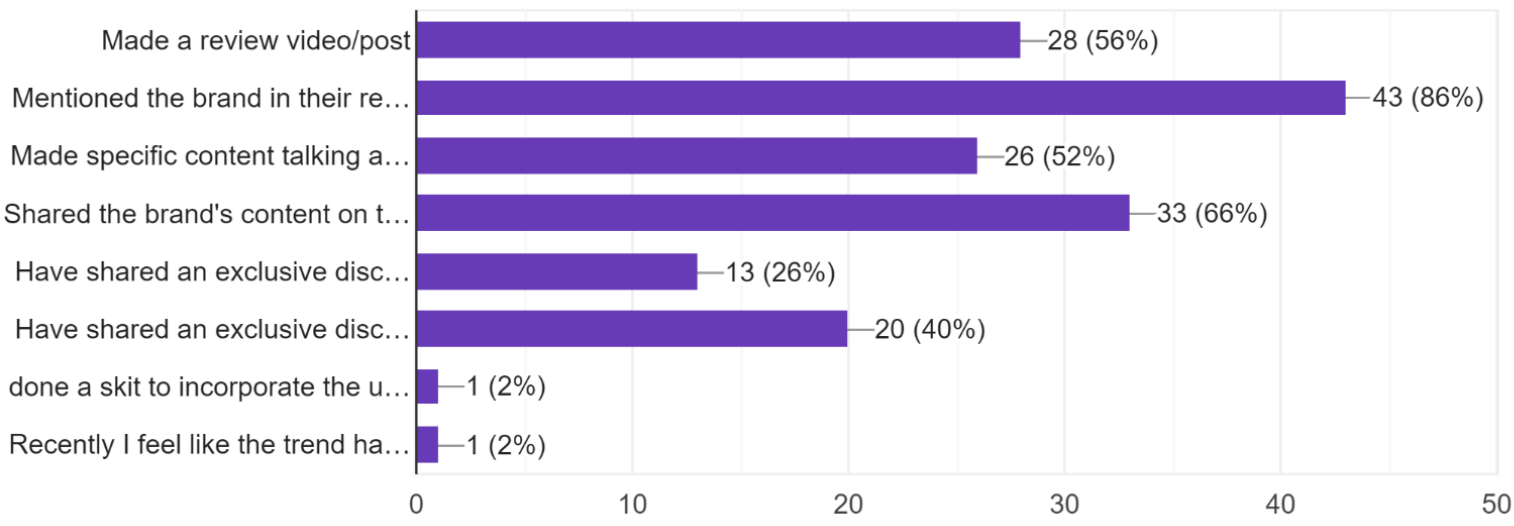

Almost every user chose more than one option with the second, fourth and first way of content integration being the most popular among both influencers and users. All the options were voted for but not as prominently as most of them making it clear that influencer content takes a lot of forms and is marketed exclusively as well.

Majority of users have seen influencers casually mention the brand/product in their regular posts/videos/stories or tweets which is a subtle yet effective way of marketing through an influencer. It brings the brand/product into a conversation among the followers and starts building up trust and turns into a personal recommendation from the influencer who incorporates the brand/product in their lives and hints at the benefits of it whenever they can. This is efficient and a great way to market skincare, beverages, movie promos, and more and helps the brand become a regular name in their industry.

Users have also seen influencers often sharing the brand's content on their page and urging their followers to check the brand out, buy their product, or just share their posts/products/updates on their feed for their interested followers to see. This has shown mixed results for companies as users often don't engage in such promotions since they are strictly sales/brand building-based marketing. This does give visibility to businesses especially small businesses who can benefit a lot from this type of promotion and reach a wider audience.

Another way of promotion users has seen a lot is option 5 and 6 (which are the same) wherein an influencer collaborates with a brand and they create an exclusive discount code for the influencer's followers. This discount code is exclusively shared by the influencer urging their followers to make a purchase using the code and avail a discount or a great deal. It is definitely marketed to generate more sales instead of the regular or subtle brand building. Companies with skincare products, clothing items, accessories, or even online courses engage in this form of promotion. Users feel a little compelled to buy like this as it comes from a trustworthy recommendation of their favorite influencer and they get discounts and deals in their favor.

A wildly popular way and one that has been a part of influencer marketing since the start is review videos/posts. More than half of users have chosen review content as one of the types of marketing content they have seen influencers make. This is the most direct form of influencer marketing and its practicality depends a lot on the type of brand/product, the way the influencer reviews it, and the influencer's impact on their followers. Influencers tend to create meaningful bonds with their followers and create an environment of trust and loyalty. Users tend to buy something on the recommendation of an influencer if they like the influencer, their content, and trust their taste and judgment to share a review about a brand/product.

A lot of influencers have dedicatedly been making specific content about the brand/product which is not just reviews but also skits, music acts, role-plays, performances and so much more. They try to curate content that matches the brand/product features and prepare their mainstream content but for marketing purposes. This is smart and effective marketing if pulled off well and as per the results of the survey, a lot of users have come across such content often.

A few users have pointed out how influencers have also made engaging content that doesn't seem like an advertisement but promotes the brand/product quite effectively. They keep it simple and genuine so users don't feel like it's forced and hence get interested in the brand/product. This has worked quite well for a lot of offbeat companies and influencers who have creatively used their talents to make content that promotes them subtly but with impact. 
It is evident that users have come across all types of influencer marketing content whether they are effective or not and it has made a considerable impact on users the majority of the time.

Q 5 Does influencer marketing content appeal to users and make them want to check out a brand or buy a product?

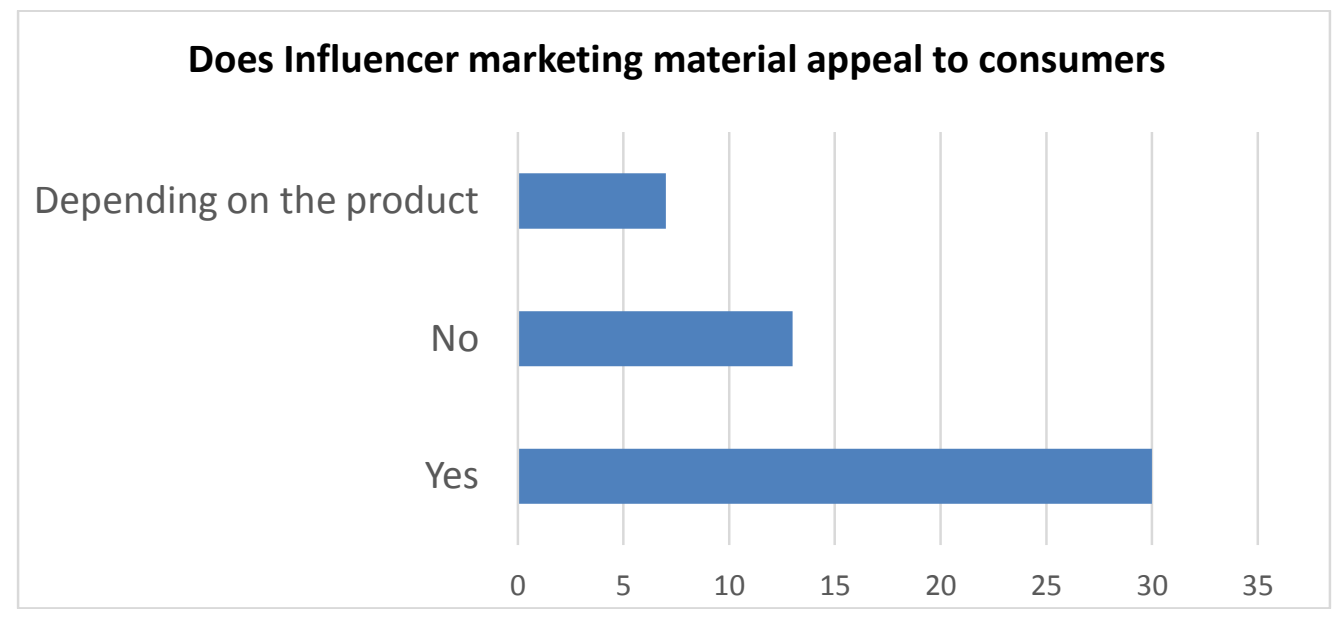

A majority of consumers in the survey answered Yes to this question which speaks volumes of how impactful and appealing influencer marketing can be at times. With how widespread it is and how frequently it shows up on people's feeds, well-made content often catches the eye and even if a consumer doesn't make a purchase, they are likely to check the brand's page or website.

A lot of users in this survey who said Yes believe that products/brands promoted by influencers seem useful, genuine, tested out, high quality, trustworthy, appealing, convincing and are available at a good deal. They also believe that influencers they like will only suggest them good products/brands and in the best interest of their followers. And if the content is well made then users may look into the brand if not buy from it. Users have also mentioned that the likability of an influencer directly impacts the likability of a product/brand hence affecting the purchase decisions of consumers.

A handful of survey participants said No to the question with a justification that since influencers are paid to promote, they do it to earn and often don't use the products they promote themselves. And often the brand/product being promoted isn't that good and that consumers should look into user reviews instead of influencer promotions before making a decision to buy. Some participants argued that influencer marketing content looks forced at times and is not appealing enough to make someone buy a product. Users have also mentioned self-research and word of mouth as a better option to make a purchase decision.

While a small part of the survey participants have said that it depends on their need. If they see a product being marketed and they need it then the marketing content is more appealing to them as it satisfies their needs. If they don't need the product they may not find it as appealing and important and either they won't engage or engage to the extent of checking out the brand. A lot of these maybes also depend on the price of the product and the ethics and values of the brand as well as the influencer. The more these resonate with the consumer, the more likely they are to make a purchase or engage with a brand. 
Q 6 Have consumers ever purchased a product or want to purchase a product that was promoted by an influencer?

\section{How many consumers have/want to buy a product promoted by an influencer}

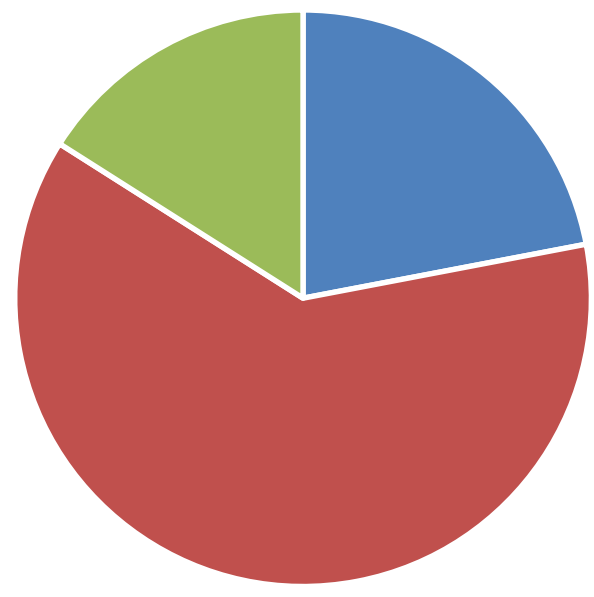

- Have Will buy in the future Don't want to

The appeal of influencer marketing has definitely got a hold of most of the participants and the majority of them to have their eyes on many products they want to buy and will buy in the future if possible. Most of them discovered said products and their brands through the influencer and have been monitoring how effective and useful it is to make a sound decision. While others have their heart set on buying them as they look genuine and trustworthy and the influencer has been using it too.

A few of the participants have ended up purchasing clothes, makeup, accessories, gaming equipment, and even ordered food from places promoted by an influencer. They have availed the influencer's discount codes and have majorly made these purchases because they discovered the products through the influencer, were convinced by the marketing, and loved the description of the product as given by an influencer they trust. All of these participants have mentioned that they are satisfied with their purchases and will make more such future purchases in the future on the recommendation of influencers.

A minority of the group completely refused to buy a product promoted by an influencer for many reasons including the exaggerated marketing technique, sales-minded promotion, and their personal disconnect with influencers. Some have also said that most of the marketed products don't fit their budgets or needs or that they don't believe or fall for this type of marketing and will choose otherwise. 
Q 7 Do consumers think influencer marketing is more effective than traditional marketing and has been more impactful especially during the pandemic?

\section{Is influencer marketing more impactful than traditional marketing for consumers?}

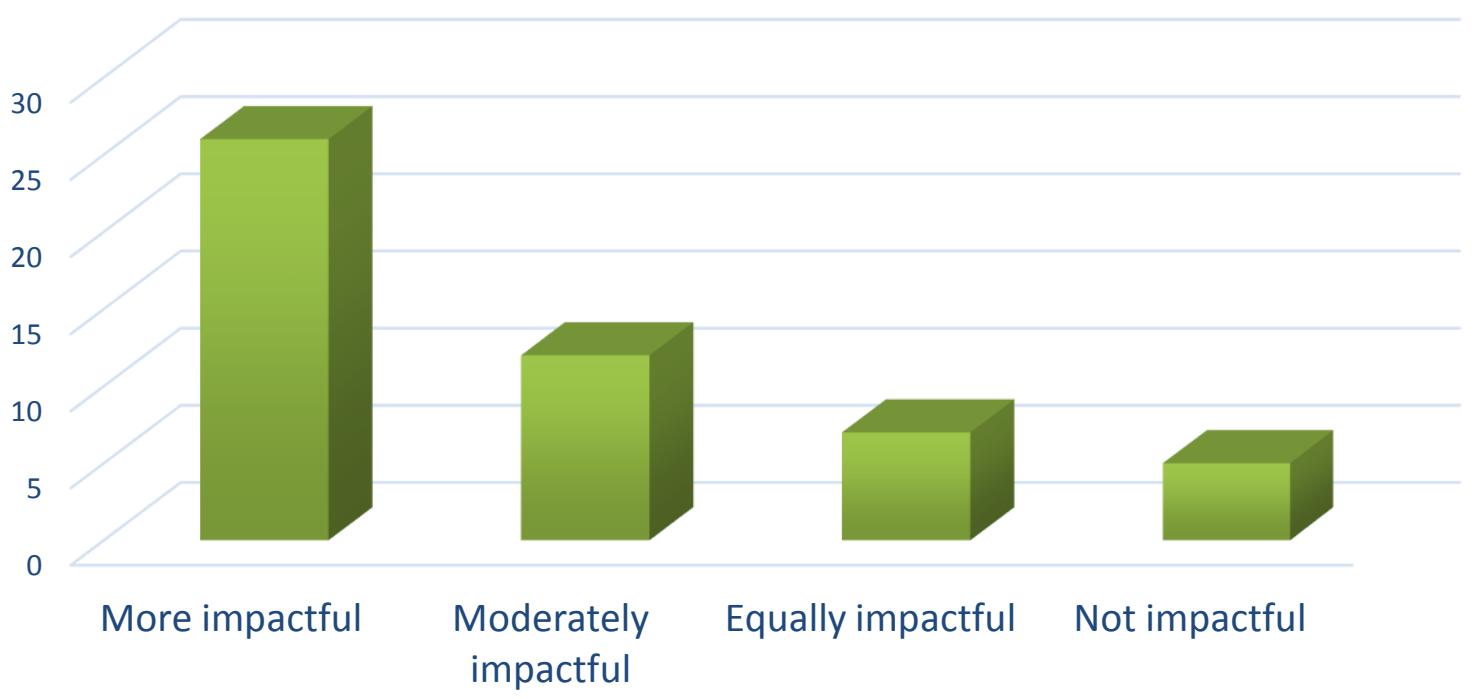

Number of Consumers

Half of the consumers part of the survey agree that influencer marketing is more effective and impactful than traditional marketing. Especially citing the pandemic as a booster for this form of marketing. These users believe that influencers become "friends" with their followers, posting tidbits of their daily life and incorporating advertisements effortlessly making them seem more convincing.

Some other users mention that influencer marketing is more effective than traditional marketing because people are more likely to engage with products if it's coming from someone they've chosen to connect with whose values and judgments match their own. It is also a highly relatable source for them as compared to traditional marketing forms. Mainly because consumers tend to follow influencers similar to their taste and body shape, getting a better idea of what may suit their lifestyle more which traditional marketing eliminates.

Consumers also feel it is more impactful because it reaches a large audience, builds relations between fans-influencers-brands, and feels more personal and specifically catered to than traditional forms. Moreover, it is deemed as a turning marketing tac tic for businesses as well, bringing in more success than traditional forms do.

Some users held a middle-ground view about this where they believe that target audience, product, brand, influencer, and their content are variables that determine influencer marketing's success which can at times be less effective than traditional techniques and sometimes more effective. Its effectiveness depends on the situation and as a marketing technique working only on social media, it is limited but impactful in its own ways.

There were also users who consider both marketing forms to be equally effective as they both target and impact different people differently. Both have the same end goal but work differently and while influencer marketing is effective for the young generation, traditional marketing is still much needed for the older ones where it is still quite effective.

And a few consumers simply refuse to believe that influencer marketing is more impactful than traditional marketing. They refer to influencer marketing as a temporary form of marketing that gained traction during the pandemic and will die down as the pandemic dies down. It is effective but for a limited number of people and still poses gaps that are filled by traditional marketing strategies. 
Q 8 Do consumers feel like influencer marketing has benefited small businesses during the pandemic by helping them reach their target audience and build their brand to get more sales during these tough times?

\section{Was influencer marketing beneficial to small businesses during the pandemic}

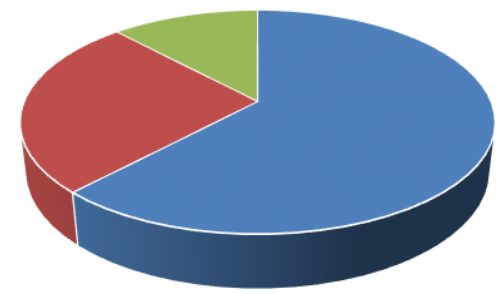

- Yes definitely - To a certain extent $\square$ Not really

A majority of the survey participants agree that influencer marketing has helped small businesses during the pandemic by amplifying them and their products and helping them reach bigger audiences to increase sales. Since online shopping increased by ten folds, a lot of consumers found that they were introduced to some amazing small businesses through influencers who helped the business grow by promoting them.

Some consumers have testimonies as to how an influencer has helped skyrocket a small business by continuously making purchases through them, taking photos of it, posting it on their socials, and tagging them for more visibility. Users also mention the rise of social media users due to the pandemic as a key element in making people influencers and being loyal consumers to influencer marketing.

Some users partially agree as they have seen both successes for small businesses and also losses. In their opinion, small businesses that could afford an influencer gained this traction while businesses without a big influencer budget were left out. It benefited some but overshadowed the others. Either way for users, influencer marketing did produce some productive results at times hence they partially do credit it for helping some small businesses make it through the pandemic.

A good number denied that influencer marketing helped small businesses during the pandemic as none of the influencers they came across vouched for smaller brands. In fact, they believe that influencer marketing only benefits big companies that can afford it whereas the smaller ones find it harder to get an influencer to market them.

\section{Conclusion}

The survey findings to get a consumer view on influencer marketing have produced mixed results with more inclination towards the positives than negatives. More than half of the participants believe that influencer marketing has had a significant impact on their purchase decisions and their overall lookout on what type of marketing convinces them to buy a product or engage with a brand. It is evident through various online platforms and researches that influencer marketing has proven to be very impactful and has played a key role in many consumers' purchase decisions.

A lot of consumers who are also avid social media users agree to being exposed to influencer marketing content every day and hence being an indirect target of various advertisements all over social media. A lot of them have at some point checked out the brands and products mentioned in these influencer advertisements which have either resulted in a purchase or a thought for a purchase in the future.

Most consumers agree that while they see influencer marketing content through influencers they follow, they also come across this content from influencers they don't follow. Which still has an impact on their purchase decision as they do check the brand or product out. This proves that even indirect influencer marketing has made consumers aware of brands and products and made them contemplate a purchase or has resulted in a real purchase.

Internet trends have shown that during the pandemic, a lot of creators rose to garner fame and became influencers and then further became influencers who promote brands. It became the new trend on social media and it has benefited plenty of companies who needed a way to continue business during a rather dull period. There has been substantial growth in the number of users who consume influencer marketing content on a daily and the number of users who go through the four stages of the AIDA model as they approach a purchase/not purchase stage of decision making.

Small businesses, big businesses, medium businesses, and homegrown businesses have all received much attention once they were 
promoted by a popular influencer and it has impacted their sales majorly because not only did they reach their target audience through a mediator, they did so through a popular one among a big group of people who will make purchases if recommended to them by said influencer.

Not only have many consumers come to be regular buyers of things marketed through influencer marketing, but they also think it is the best type of marketing to get to their heart and mind and place a product in it. Consumers also believe the way these are marketed by influencers through skits, funny videos, satirical content, heartwarming videos and more really makes the marketing 10 times more convincing but also genuine.

A good part of the regular influencer marketing enthusiasts have been regular purchasers of products that influencers heavily market and in their opinion, those are some of their best purchases and they will continue to buy things if an influencer has promoted it well and it fits their needs. Lots of others have been satisfied with what they bought through an influencer's recommendation and they find it a more trusting recommendation given to them to suit their tastes so they feel like they are exclusively catered to.

In conclusion, we can say that influencer marketing holds deep grounds for consumers' purchase decisions and has at least 7/10 times made a consumer buy a product or consider buying one. It has helped consumers get aware of many brands, products, and options of products to buy from while also giving them incentives in the form of discounts and deals. It has helped many consumers learn about market trends and things to buy and from where helping them make a sound decision when they decide to put in their money and energy into making a purchase. For many, it has become an ultimate recommendation source that they trust immensely and cross-check with before making a purchase. And for many, it is idolization turned into a parallel expression of relativity with the influencer they take a product/brand recommendation from. Either way in recent times it has become a more concrete phenomenon and has shown major impacts on consumers, all ages and tastes, and their purchase decisions and behaviors.

It is safe to conclude that influencer marketing holds an upper hand in the market when it comes to influencing their target groups effectively and turning it into a one-time or a regular purchase and engagement pattern.

\section{References}

[1] Aka K. (2016). New research: The value of influencers on Twitter. New York

[2] Barker S. (2020). How Social Media Influencers Can Impact Your Customers' Purchase Decisions

[3] Cobain D. (2020). How Influencer Marketing Affects Consumer Buying Behaviour. 2

[4] Diggit agazine. (2020). The impact of instagram influencers

[5] Foster J. (2019). Why Influencer Marketing is Creating Huge Returns for Businesses

[6] Influencer Marketing Hub. (2019). What is Influencer Marketing: An in Depth Look at Marketing's Next Big Thing

[7] Kramer S. (2019). The Impact of Influencer Marketing on Consumers

[8] Levin A. (2020). Influencer Marketing for Brands: What YouTube and Instagram Can Teach You About the Future of Digital Advertising. New York: Research Gate

[9] Mahal M. (2020). TikTok ban and its business impact on Influencer Marketing Industry

[10] Makropoulos M. (2020). 2020 Influencer Marketing Trends

[11] Referal Rock Learn. (2020). How Influencer Marketing Can Build Your Brand. 2-8

[12] Stefan Zak M. H. (2020). The role of influencers in the consumer decision-making process. Research Gate

[13] Wiley K. (2019). 4 Ways Influencers Have Changed Consumer Buying Behavior

[14] Working influencer. (2019). Tips for becoming an influencer 